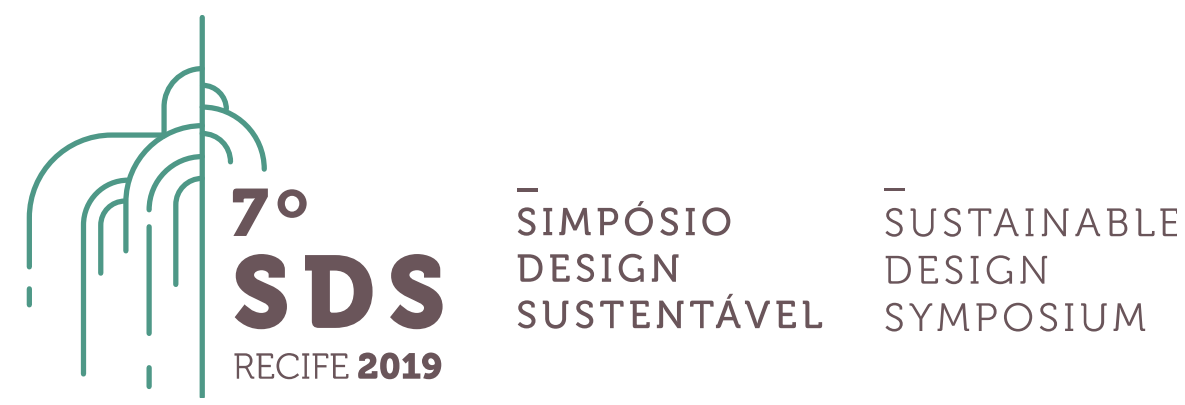

\title{
Sustentabilidade, inovação e emprego de materiais naturais no design brasileiro premiado: móveis e têxteis comtemplados pelo Prêmio Design do Museu da Casa Brasileira, de 2012 a 2016
}

\author{
Débora Harumi Matsuda ${ }^{1}$, Dra. Cyntia Santos Malaguti de Souza ${ }^{2}$ \\ ${ }^{1}$ Universidade de São Paulo, Faculdade de Arquitetura e Urbanismo, Curso de Design, São Paulo \\ ${ }^{2}$ Universidade de São Paulo, Faculdade de Arquitetura e Urbanismo, Departamento de Tecnologia da Arquitetura, São \\ Paulo
}

\begin{abstract}
Resumo. O presente artigo apresenta os resultados finais de uma pesquisa em nível de iniciação científica, cujo objetivo principal foi investigar se e como a 'sustentabilidade' e a inovação foram entendidas e traduzidas em um conjunto de objetos premiados pelo Museu da Casa Brasileira, com foco em duas categorias que fizeram uso de materiais naturais: móveis e têxteis. Com base em uma pesquisa bibliográfica acerca das diretrizes da sustentabilidade, da inovação tecnológica e do uso de materiais naturais no design, foram estruturados os parâmetros de análise dos produtos. Dentro desse recorte, foram selecionados 17

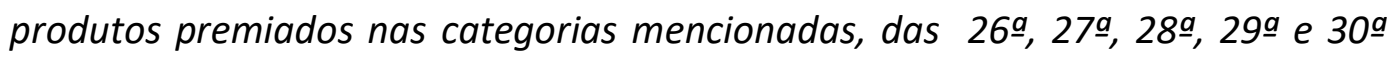
edições do Prêmio Design MCB, e informações técnicas sobre seu design $e$ produção foram coletadas através de pesquisa bibliográfica, documental e de contato com seus autores (por meio de envio de formulário com questões abertas e fechadas), abrangendo: fundamentos de inspiração, materiais empregados $e$ processos de produção, assim como aspectos de inovação e sustentabilidade baseados na roda de estratégias de ecodesign. A análise de cada objeto e a comparação entre eles possibilitou identificar os objetivos e pressupostos de seu desenvolvimento, ênfases, percepções associadas à sustentabilidade e inovação, assim como o protagonismo dos materiais naturais nesse contexto.
\end{abstract}

Palavras-chave. Prêmio Design Museu da Casa Brasileira, materiais naturais, sustentabilidade, inovação.

\section{Introdução}

Segundo Manzini e Vezzoli (2008), nossa sociedade está passando por um período de transição, caracterizado por um processo de desmaterialização do atual sistema de produção e consumo. O designer pode ser um agente fundamental nesse processo, ao pensar em orientações estratégicas voltadas a um sistema produtivo regenerativo, visando atingir um objetivo sustentável sem provocar catástrofes sociais e culturais. 
Nesse contexto, e tomando como premissas a riqueza e diversidade de recursos naturais presentes em nosso país e a necessidade do desenvolvimento de processos sustentáveis em relação a sua utilização, a pesquisa aqui apresentada investigou a utilização de materiais naturais por designers brasileiros no desenvolvimento de produtos, identificando os materiais e processos explorados, bem como as suas preocupações relacionadas à sustentabilidade.

Conceitua-se material natural como "todo aquele extraído pelo homem da natureza, de forma planejada ou não, sendo que para a sua utilização artesanal ou industrial não tenha havido modificações profundas em sua constituição básica" (LIMA, 2006, p. 85). Os materiais naturais podem ser de origem orgânica, abrangendo aqueles de procedência animal e vegetal, como madeiras, fibras e determinados polímeros; ou inorgânica, que envolvem os minerais em geral.

Em função de sua menor resistência a impactos, variações constantes nas condições do ambiente e altos custos de produção, os materiais naturais vêm sendo facilmente substituídos por materiais sintéticos. Em contrapartida, apresentam verdadeiras possibilidades de renovação natural e de renaturalização (absorção pela natureza quando descartados), além de, muitas vezes, oferecerem maior nível de conforto em situações onde há o contato humano. $E$ ainda, frequentemente seu manejo está associado a saberes tradicionais de determinadas regiões, podendo contribuir para a melhoria das condições de vida de populações frágeis, em ações de designers em parceria com artesãos; e em outras vezes, a pesquisas de ponta voltadas a sua aplicação em compósitos de alto desempenho e geradores de menor impacto ambiental. É por esses aspectos que os materiais naturais apresentam um alto potencial de inovação no campo do design, seja do ponto de vista ambiental, social ou tecnológico. A perfeita combinação entre material e design, atrelada às questões de sustentabilidade, permite a criação de soluções significativas para as pessoas, causando impactos positivos na sociedade em que vivemos.

Uma das maneiras de se difundir este tipo de abordagem é através das exposições de objetos de design premiado. Elas contribuem não somente para enriquecer as ideias de aplicação de materiais em diversas categorias de produtos, como também para "permitir reflexões sobre as preocupações do design ao longo do tempo, na busca por apresentar soluções aos anseios da sociedade da sua época" (CARNASCIALI, 2014, p. 123). Considerando que a premiação de design mais consolidada e importante no Brasil é o Prêmio Design do Museu da Casa Brasileira - MCB, com mais de trinta anos de existência e recebendo, anualmente, mais de 500 inscrições de todo o país, esta pesquisa tomou como objeto de investigação um conjunto de 17 objetos premiados, já em produção, a partir das edições do prêmio realizadas entre os anos de 2012 e 2016 (26ạ , 27ạ, 28ạ , 29a e 30a). A seleção das categorias de móveis (12) e têxteis (5), que resultou foi decorrente da constatação da ocorrência de maiores quantidades de produtos premiados em ambas, com emprego de materiais naturais - coincidindo também geralmente, com menor complexidade, menores escalas de produção e controle maior do processo pelo designer. Com o desenvolvimento desse estudo, buscou-se enriquecer a compreensão sobre o uso de materiais naturais, técnicas e processos aplicados, e identificar as abordagens relacionadas à sustentabilidade e inovação no contexto do design brasileiro. Procurou-se analisar o produto vencedor não como um objeto acabado, mas sim como um indicador de intenções do designer, atribuindo primazia aos processos de formulação em relação ao produto final (INGOLD, 2000).

A pesquisa vinculou-se a um projeto de dimensões maiores, que vem sendo realizado em conjunto com o Museu da Casa Brasileira.

\section{Materiais e métodos - roda de estratégias de ecodesign}

A roda de estratégias de Ecodesign (BREZET; HEMEL, 1997), também chamada Estratégias de projeto de ciclo de vida, ajuda na visualização de estratégias que podem ser seguidas para 0 Ecodesign. O primeiro conjunto de estratégias da roda, "New concept development", está mais 
relacionado a conceitos inovadores (que, inclusive ultrapassam a ideia de desempenho ambiental do produto muitas vezes associada ao conceito de ecodesign), envolvendo a adoção de estratégias como desmaterialização, uso compartilhado, integração de funções ou otimização da função. Os demais conjuntos estão relacionados à otimização do ciclo de vida do produto.

A partir da roda de estratégias de Ecodesign, foi construído um quadro que segue o mesmo sistema (figura 1), para análise dos objetos investigados nesta pesquisa. Foram realizadas, porém, algumas modificações, com base em pesquisas bibliográficas, para melhor adequação aos objetivos definidos, com o intuito de aprimorar a análise dos produtos.

Figura 1 - Proposta de roda de estratégias de ecodesign para análise dos produtos premiados

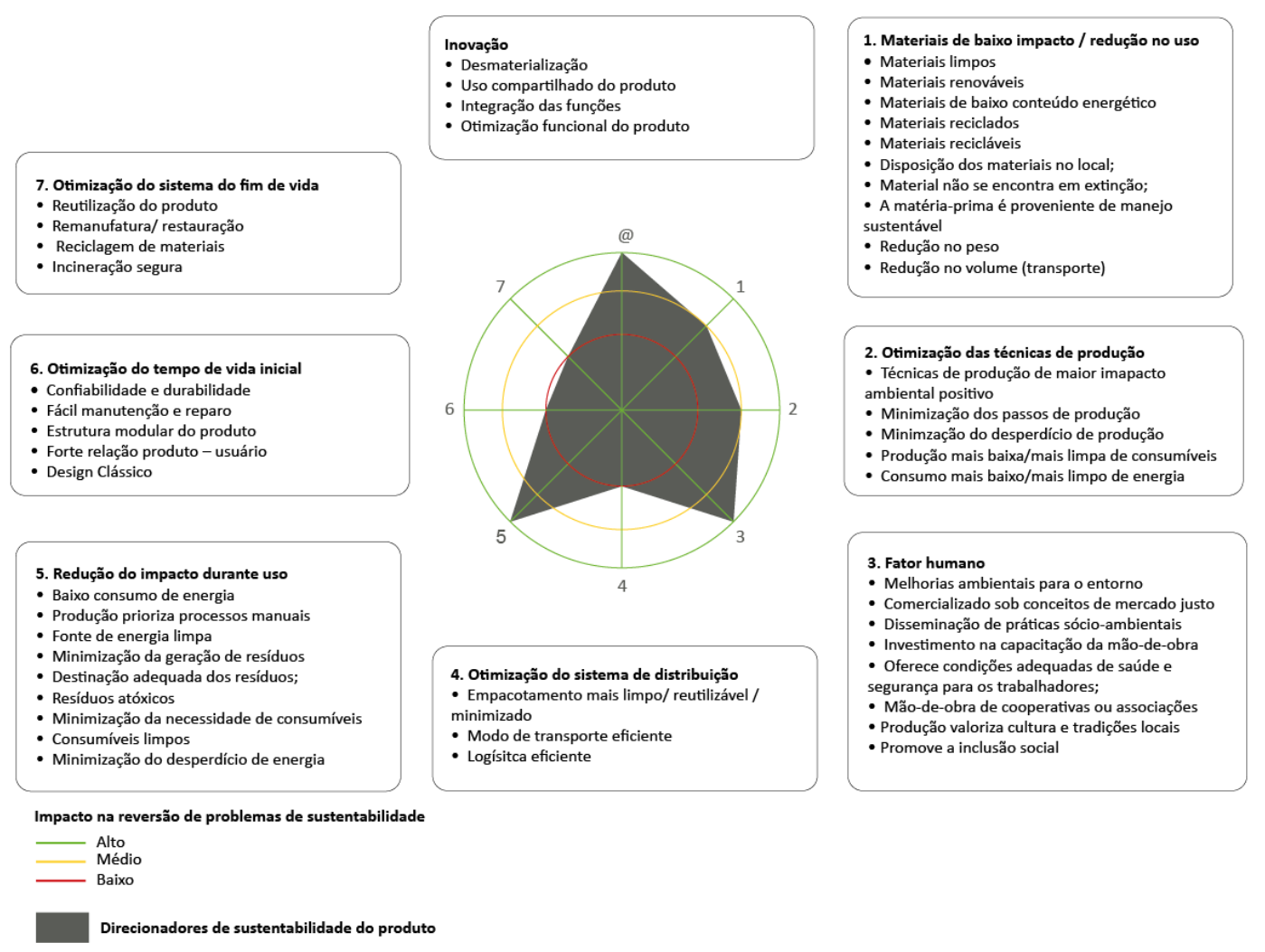

Fonte: Adaptado de BREZET \& HEMEL, 1997.

A roda adaptada é constituída de 8 categorias de estratégias, incluindo a consideração do fator humano, que não estava presente no modelo de Brezet e Hemel (1997). A caracterização do produto analisado em relação às estratégias empregadas foi apresentada de maneira gráfica (área cinza), de acordo com o seu nível de impacto sustentável. O impacto sustentável de cada estratégia foi medido de maneira qualitativa, sendo que o círculo vermelho (mais próximo do centro) simboliza baixo impacto sustentável (positivo), o amarelo, médio impacto, e o verde, alto impacto sustentável. Os critérios de gradação relativa dos impactos em baixo, médio e alto foram baseados na tabela de sustentabilidade de Brian Dougherty (2011), que usa as cores referidas para avaliar o impacto dos materiais e processos de produção; a diferença é que ele analisa os impactos negativos e aqui, analisa-se os impactos positivos. Dessa forma, diante da impossibilidade de acesso a dados quantitativos do impacto ambiental e humano relacionados ao ciclo de vida de cada produto, considerou-se que esta ferramenta poderia auxiliar numa avaliação preliminar, suficiente para atender aos objetivos desta pesquisa. A figura 2 apresenta os critérios norteadores da avaliação para cada uma das 8 categorias de estratégias, que funcionaram como guias na avaliação qualitativa dos produtos. 
Figura 2 - Critérios norteadores para avaliação

\begin{tabular}{|c|c|c|c|}
\hline INOVAÇĀO & MATERIAIS & TÉCNICAS DE PRODUÇĀO & FATOR HUMANO \\
\hline $\begin{array}{l}\text { - Novo conceito; nova } \\
\text { aplicação. }\end{array}$ & $\begin{array}{l}\text { - Feito com recursos } \\
\text { obtidos de forma } \\
\text { sustentável e renováveis; } \\
\text { sem toxidade conhecida. }\end{array}$ & $\begin{array}{l}\text { - Envolve incorporação } \\
\text { moderada de energia. }\end{array}$ & $\begin{array}{l}\text { - Gera impacto social } \\
\text { positivo para mão de } \\
\text { obra produtora e para o } \\
\text { usuário. }\end{array}$ \\
\hline $\begin{array}{l}\text { - Conceito existente } \\
\text { implementado através de } \\
\text { uma nova aplicação. }\end{array}$ & $\begin{array}{l}\text { - Feito com fonte renovável } \\
\text { convencional; }\end{array}$ & $\begin{array}{l}\text { - Envolve baixa } \\
\text { incorporação de energia. }\end{array}$ & $\begin{array}{l}\text { - Gera impacto social } \\
\text { positivo para mão de } \\
\text { obra produtora ou para o } \\
\text { usuário. }\end{array}$ \\
\hline $\begin{array}{l}\text { - Conceito e aplicação } \\
\text { existentes. }\end{array}$ & $\begin{array}{l}\text { - Feito com recurso não } \\
\text { renovável; }\end{array}$ & $\begin{array}{l}\text { - Envolve alta incorporação } \\
\text { de energia. }\end{array}$ & $\begin{array}{l}\text { - Não foca na geração de } \\
\text { impacto social. }\end{array}$ \\
\hline DISTRIBUIÇĀO & $\begin{array}{l}\text { REDUÇĀO DO IMPACTO } \\
\text { DURANTE USO }\end{array}$ & $\begin{array}{l}\text { OTIMIZAÇĀO DO TEMPO } \\
\text { DE VIDA INICIAL }\end{array}$ & FIM DE VIDA \\
\hline $\begin{array}{l}\text { - Envolve baixa } \\
\text { incorporação de energia. }\end{array}$ & $\begin{array}{l}\text { - Envolve baixa } \\
\text { incorporaçáo de energia. }\end{array}$ & $\begin{array}{l}\text { - Alta durabilidade } \\
\text { (adoçáo de medidas para } \\
\text { elevar a durabilidade do } \\
\text { produto). }\end{array}$ & $\begin{array}{l}\text { - Totalmente reciclável; } \\
\text { totalmente compostável; } \\
\text { reutilizável. }\end{array}$ \\
\hline $\begin{array}{l}\text { - Envolve incorporaçáo } \\
\text { moderada de energia. }\end{array}$ & $\begin{array}{l}\text { - Envolve incorporaçäo } \\
\text { moderada de energia. }\end{array}$ & - Durabilidade média. & $\begin{array}{l}\text { - Parcialmente reciclável, } \\
\text { compostável ou } \\
\text { reutilizável. }\end{array}$ \\
\hline $\begin{array}{l}\text { - Envolve alta incorporação } \\
\text { de energia. }\end{array}$ & $\begin{array}{l}\text { - Envolve alta incorporaçáo } \\
\text { de energia. }\end{array}$ & - Baixa durabilidade. & $\begin{array}{l}\text { - Incineração; } \\
\text { - Requer aterro sanitário } \\
\text { convencional ou para } \\
\text { resíduos perigosos. }\end{array}$ \\
\hline
\end{tabular}

Fonte: As autoras.

\section{Resultados e discussões}

A Tabela 1 apresenta o conjunto de produtos analisados, classificados por edição do prêmio e categoria correspondente. Como se pode observar, tem-se 4 bancos, 3 poltronas e 2 mesas, 1 aparador e 1 escrivaninha, entre os móveis; 2 tecidos aplicados à decoração de interiores (Franja e Tapete Paulistano) e 3 à moda (Velaturas, Quadrados e Oricla). A figura 3, por sua vez, ilustra uma das fichas elaboradas com as informações obtidas de cada produto.

Tabela 1 - Relação de produtos analisados

\begin{tabular}{lll}
\hline Edições & Mobiliário & Têxteis \\
\hline $26 \underline{a}$ & $\begin{array}{l}\text { Mesa Dinn } \\
\text { Banco Charlotte } \\
\text { Poltrona Alice }\end{array}$ & $\begin{array}{l}\text { Franja } \\
\text { Tapete Paulistano }\end{array}$ \\
\hline $27 \underline{a}$ & Banco Osso & \\
\hline $28 \underline{a}$ & Poltrona Sopro & Velaturas \\
\hline $29 \underline{a}$ & Mesa Bank & Quadrados \\
& Biombo Conogó & \\
\hline
\end{tabular}


Poltrona Kei

Aparador Harmonia

Oricla

Escrivaninha São Basílio

\section{Fonte: As autoras}

Figura 3 - Exemplo de ficha com informações obtidas sobre cada produto

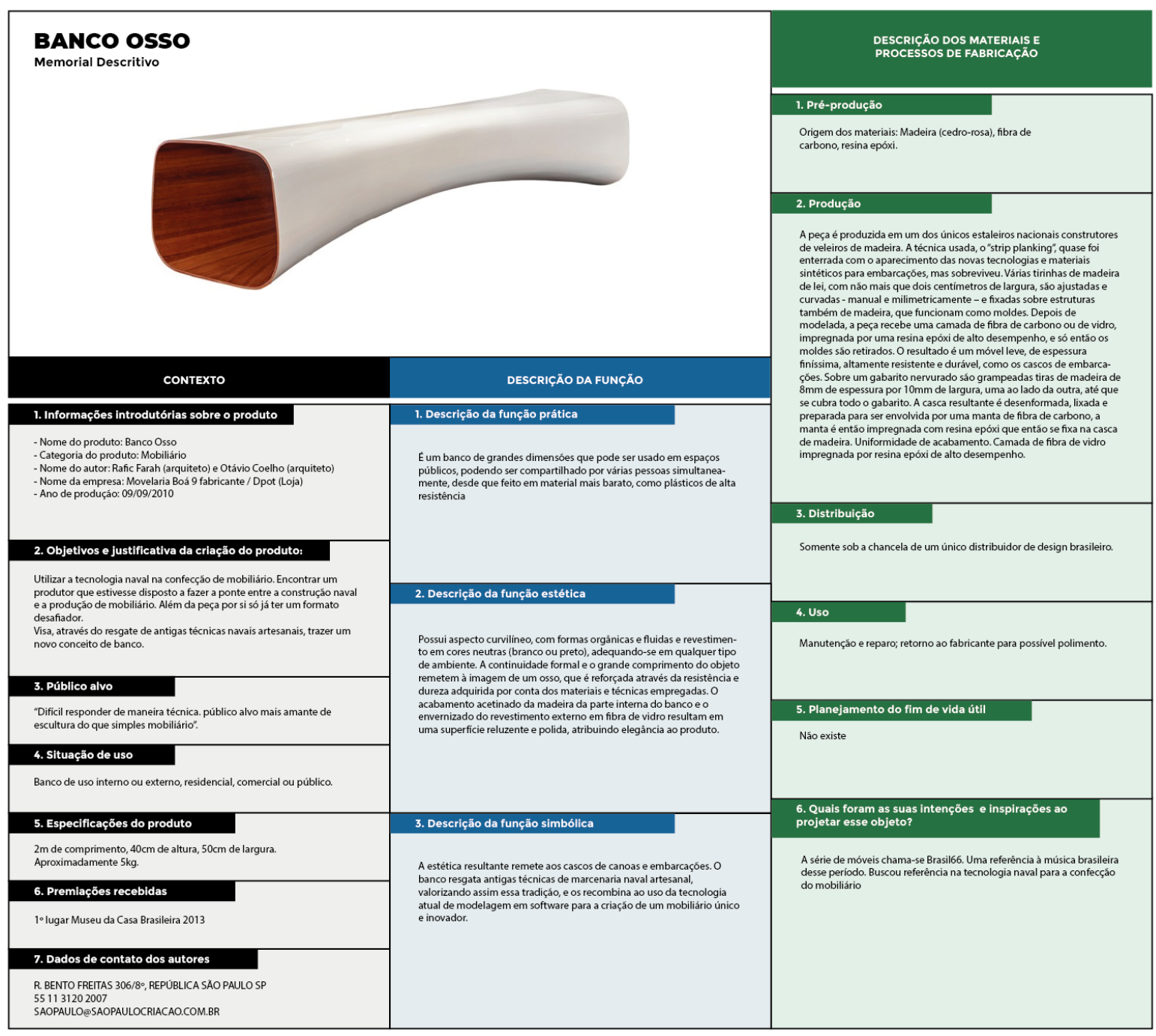

Fonte: As autoras.

A sequência de Rodas de Estratégias de Ecodesign, construídas a partir das informações reunidas, apresentada na figura 4, permite uma visualização geral do desempenho de cada produto de acordo com os critérios definidos pela pesquisa, agrupados por categoria.

Figura 4 - Rodas de estratégias de ecodesign relativas aos produtos analisados 

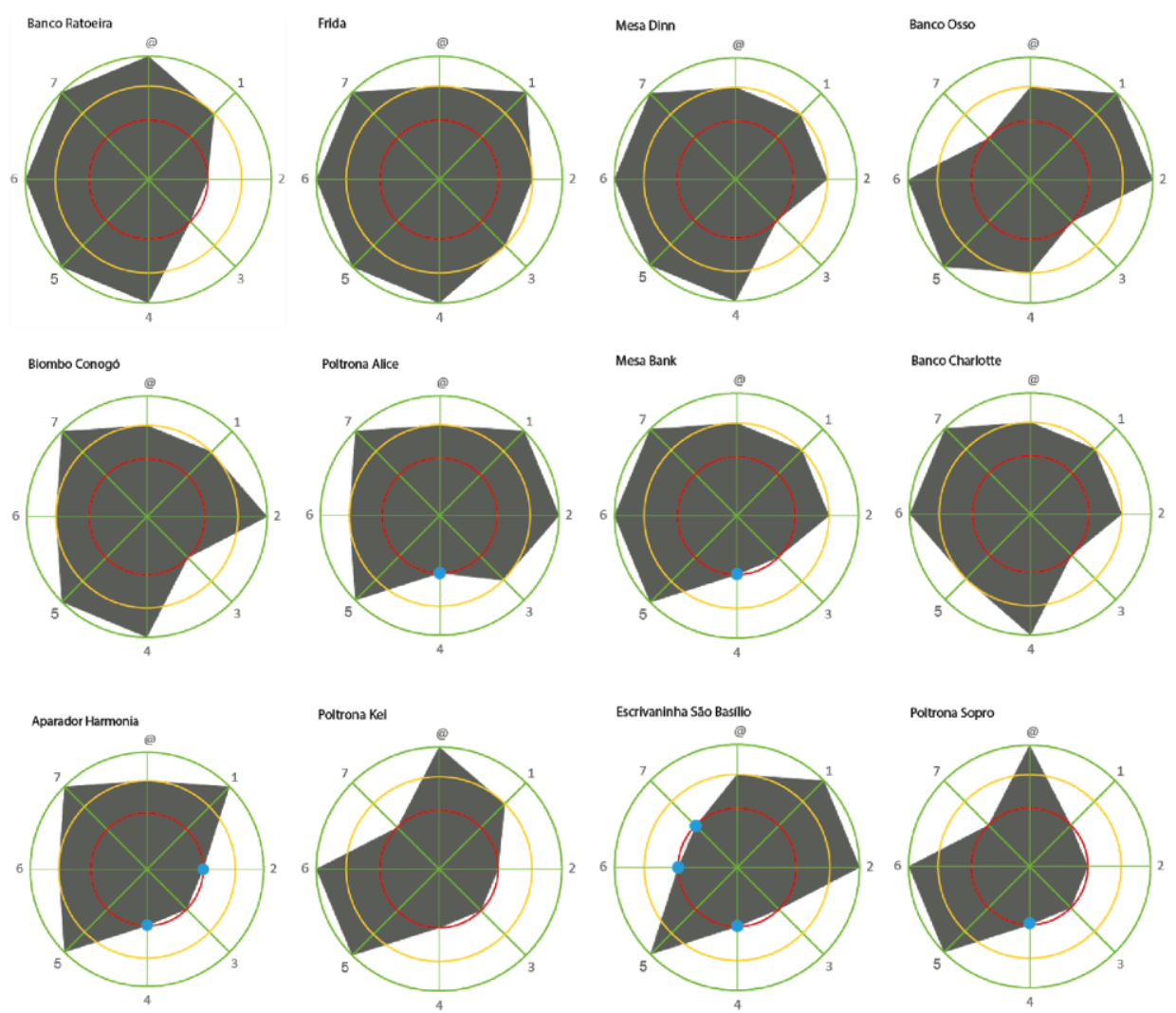

Têxtil
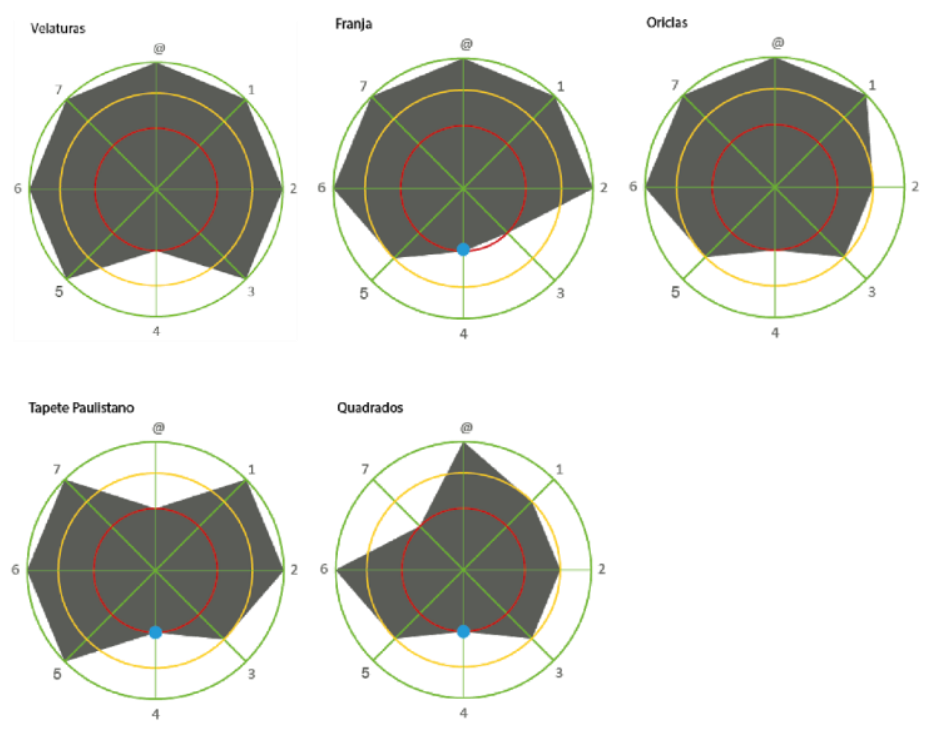

Fonte: As autoras.

Em relação às estratégias mais enfatizadas pelos autores, A figura 5 , a seguir, permite uma visualização quantitativa mais adequada, na categoria de mobiliário. Observa-se que os produtos apresentam majoritariamente alto impacto sustentável (positivo): na redução do impacto durante uso (91,66\% dos móveis analisados), na otimização do tempo de vida (66,66\%) e na otimização do sistema de fim de vida (66,66\%). Apresentam majoritariamente médio impacto sustentável em relação ao uso do material (50\%) e boa parte dos móveis apresentam baixo impacto sustentável 
em fator humano (83,33\%) e em otimização do sistema de distribuição (50\%). Já em relação à otimização das técnicas de produção, observa-se uma mesma porcentagem entre baixo, médio e alto impacto sustentável.

Figura 5 - Estratégias de ecodesign predominantes na categoria de mobiliário

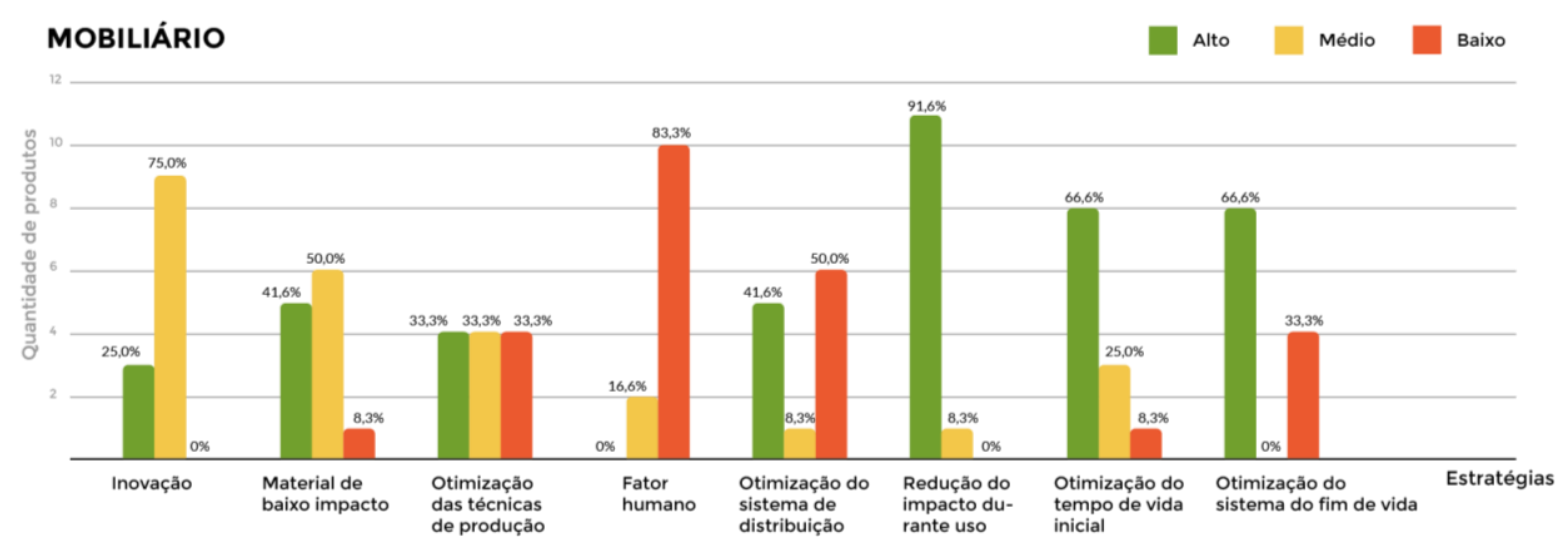

Fonte: As autoras

No que diz respeito às ênfases relacionadas ao emprego dos materiais, observou-se a busca dos autores em explorar os materiais naturais, com preocupação em relação à procedência e destinação dos mesmos. Alguns empregaram madeiras típicas da região Norte (cumarú, freijó) para a fabricação dos objetos, sendo que os autores atuam na região sul e sudeste, havendo uma elevação de custos no transporte de matéria-prima. Foi possível notar também uma grande preocupação com a durabilidade do produto, na escolha de materiais como a madeira maciça, ou em certos casos, no emprego de uma estrutura mais resistente de metal e no acabamento com revestimento de lâmina de madeira, para evitar a ferrugem e manter a aparência da madeira, remetendo a uma ideia de conforto nos espaços. Além disso, a maioria dos objetos são passíveis de manutenção, sendo que em certos casos, o serviço de reparo é disponibilizado pela própria empresa.

A produção e fabricação do produto ainda despende muita energia, principalmente para processamento da madeira e demais componentes estruturais. No entanto, alguns designers acabam encontrando soluções para esse problema, mesclando técnicas industriais com trabalho artesanal, reduzindo a incorporação energética; ou buscam, através de soluções estruturais, reduzir etapas dos processos de produção. Com relação à distribuição do produto final, excetuando-se o projeto da Banqueta Frida, não foram evidenciadas iniciativas para projetar móveis facilmente montáveis e desmontáveis a fim de reduzir custos de transporte e de estoque.

Os dados acerca do fator humano, principalmente com foco na produção, não puderam ser devidamente analisados por não dependerem única e exclusivamente dos autores. Porém, analisando-se a parte voltada para o consumidor, são poucos os autores que tiveram intenção de gerar algum tipo de inserção social das camadas mais baixas, tornando o produto mais acessível. Citando a banqueta Frida novamente, seu projeto focou nessa medida, trazendo uma solução para consumidores online que buscam praticidade no dia a dia. Os designers não só procuraram solucionar esse problema de transporte e montagem, que gera incômodo para muitas pessoas, como também a redução de custos, tornando o produto mais acessível para a classe média.

A figura 6, a seguir, permite uma visualização quantitativa mais adequada, em relação às estratégias mais enfatizadas pelas autoras, na categoria têxteis. Observa-se que os produtos apresentam majoritariamente alto impacto sustentável (positivo): no uso do material (80\% dos 
produtos têxteis analisados), na otimização de técnicas de produção (60\%), na otimização do tempo de vida inicial (100\%) e na otimização do sistema de fim de vida (80\%). Possui majoritariamente médio impacto sustentável em redução do impacto durante uso (60\%). Em relação à otimização do sistema de distribuição, duas autoras afirmaram não apresentar tais medidas; quanto às outras, não foi possível coletar informações suficientes.

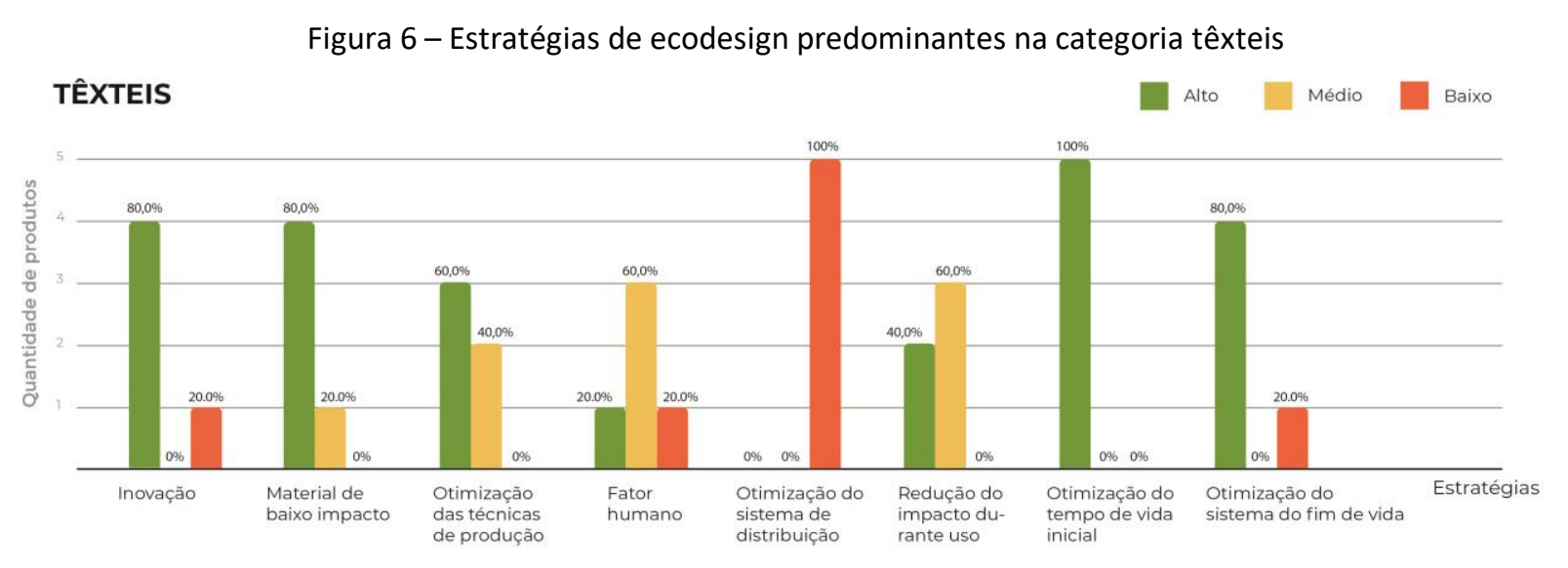

Fonte: As autoras

Diferentemente dos objetos da categoria de mobiliário, os produtos têxteis apresentam considerável otimização das técnicas de fabricação, uso de materiais de baixo impacto e inclusão do fator humano (sendo $20 \%$ de alto impacto e $60 \%$ de médio impacto). As autoras focaram bastante no uso de técnicas artesanais, proporcionando um resultado estético com certo toque de "exclusividade", na redução de incorporação energética e na disseminação de práticas socioambientais. O produto Velaturas, por exemplo, foca na otimização do processo de produção através da reutilização de material e da redução da emissão de resíduos durante a fabricação.

Com relação aos materiais empregados, existe nos produtos têxteis analisados um enfoque no reaproveitamento e reutilização de tecidos para a produção das peças, assim como no uso de tecidos recicláveis.

Existe também uma maior consideração pela geração de impacto social do que os objetos da categoria de mobiliário, através da disseminação de práticas socioambientais e da maior acessibilidade dos produtos.

Finalmente, a tabela 2 a seguir, referente ao perfil de inovação associado à sustentabilidade articula as intenções (inputs), a seleção de materiais e as implicações na solução final. Segundo Ashby e Johnson (2010), os inputs são requisitos de design expressos como características que descrevem intenções, estética e percepção.

Tabela 2 - Perfil de inovação associado à sustentabilidade

\begin{tabular}{llll}
\hline Produto & Intenções & Seleção de materiais & Implicações \\
\hline 1. Aparadora Harmonia & $\begin{array}{l}\text { Uso racional da madeira } \\
\text { nos diferentes } \\
\text { componentes. }\end{array}$ & $\begin{array}{l}\text { Peças de ipês, pinus e } \\
\text { outras madeiras } \\
\text { de diferentes } \\
\text { densidades. }\end{array}$ & $\begin{array}{l}\text { Aparadora que } \\
\text { proporciona } \\
\text { economia de material. }\end{array}$ \\
\hline 2. Frida & $\begin{array}{l}\text { Atender necessidades } \\
\text { do consumidor online. }\end{array}$ & $\begin{array}{l}\text { MDF, madeira maciça, } \\
\text { parafuso de latão e } \\
\text { borboleta de aço inox. }\end{array}$ & $\begin{array}{l}\text { Banco de montagem } \\
\text { intuitiva, embalagem } \\
\text { compacta, praticidade. }\end{array}$
\end{tabular}




\begin{tabular}{|c|c|c|c|}
\hline 3. Poltrona Kei & $\begin{array}{l}\text { Necessidade de um } \\
\text { modelo de poltrona com } \\
\text { o espaldar mais alto. }\end{array}$ & $\begin{array}{l}\text { Metal, MDF, couro de } \\
\text { origem natural e } \\
\text { tecido. Seleção por } \\
\text { inspiração na } \\
\text { arquitetura japonesa. }\end{array}$ & $\begin{array}{l}\text { Poltrona de alta } \\
\text { resistência que } \\
\text { possibilita o uso de } \\
\text { perfis mais esbeltos do } \\
\text { que os de madeira na } \\
\text { construção. }\end{array}$ \\
\hline 4. Barco Osso & $\begin{array}{l}\text { Utilizar a tecnologia } \\
\text { naval na confecção de } \\
\text { mobiliário. }\end{array}$ & $\begin{array}{l}\text { Uso de madeira (cedro- } \\
\text { rosa), fibra de carbono, } \\
\text { resina epóxi. Inspiração } \\
\text { na música brasileira dos } \\
\text { anos } 60 \text {. }\end{array}$ & $\begin{array}{l}\text { Novo conceito de banco; } \\
\text { otimização funcional. }\end{array}$ \\
\hline 5. Biombo Conogó & $\begin{array}{l}\text { Fácil produção, fácil } \\
\text { montagem. }\end{array}$ & $\begin{array}{l}\text { Madeiras maciças de } \\
\text { reflorestamento, } \\
\text { compensados ou MDF. } \\
\text { Inspiração: trabalhos } \\
\text { dos ancestrais indígenas } \\
\text { inspirados na natureza }\end{array}$ & $\begin{array}{l}\text { Biombo dobrável, que } \\
\text { pode ser recolhido; fácil } \\
\text { transporte. }\end{array}$ \\
\hline 6. Velaturas & $\begin{array}{l}\text { Necessidade do uso } \\
\text { completo da matéria } \\
\text { prima } \\
\text { (reaproveitamento). }\end{array}$ & $\begin{array}{l}\text { Material reutilizado. } \\
\text { Tafetás termo } \\
\text { adesivados, fio de } \\
\text { alumínio, linha de } \\
\text { costura. Inspiração nas } \\
\text { pinturas de tinta a óleo } \\
\text { com sobreposição de } \\
\text { camadas. }\end{array}$ & $\begin{array}{l}\text { Peça de baixa emissão } \\
\text { de resíduos, baixo } \\
\text { impacto negativo que se } \\
\text { adapta ao corpo de } \\
\text { diferentes usuários. }\end{array}$ \\
\hline 7. Oricla & $\begin{array}{l}\text { Atender a grandes } \\
\text { marcas. Criar um } \\
\text { produto "escalável" } \\
\text { capaz de solucionar o } \\
\text { problema do descarte. }\end{array}$ & $\begin{array}{l}\text { Materiais reciclados. } \\
\text { Tecido feito a partir de } \\
\text { resíduos têxteis da } \\
\text { indústria de confecção. }\end{array}$ & $\begin{array}{l}\text { Peça que incorpora a } \\
\text { reutilização de oreolas, } \\
\text { em escala industrial. }\end{array}$ \\
\hline 8. Poltrona Alice & $\begin{array}{l}\text { Proporcionar conforto. } \\
\text { Resgatar o modo de } \\
\text { sentar-se do indígena. }\end{array}$ & $\begin{array}{l}\text { Madeira certificada, } \\
\text { vinda de processo de } \\
\text { extração através de } \\
\text { manejo florestal. Lona } \\
\text { de caminhão reciclada. } \\
\text { O enchimento das } \\
\text { almofadas é em pluma. }\end{array}$ & $\begin{array}{l}\text { Estofado totalmente } \\
\text { suspenso na estrutura } \\
\text { de madeira, remetendo } \\
\text { à rede indígena. }\end{array}$ \\
\hline 9. Quadrados & $\begin{array}{l}\text { Esperava que as linhas } \\
\text { ficassem o mais } \\
\text { imperceptível possível e } \\
\text { dessem a impressão de } \\
\text { que os quadrados } \\
\text { flutuavam. }\end{array}$ & Tafetá, tule e entretela & $\begin{array}{l}\text { Tecido que traz novas } \\
\text { maneiras de estruturar a } \\
\text { matéria-prima principal. } \\
\text { O processo de corte e a } \\
\text { composição dos } \\
\text { quadrados levaram à } \\
\text { criação de um sistema } \\
\text { de modelagem } \\
\text { específico, costura e } \\
\text { acabamento próprios. }\end{array}$ \\
\hline
\end{tabular}


As informações a respeito das intenções dos autores permitiram comparar as escolhas de seleções de materiais, levando a um melhor entendimento dos resultados obtidos. A seleção de materiais pode ser feita tanto por síntese, como por meio de análise, por similaridade ou inspiração (ASHBY \& JOHNSON, 2010). A seleção por síntese consiste na seleção de materiais a partir de um banco de dados de materiais e de seus atributos; como depende de experiências anteriores de design, eles não podem sugerir soluções inovadoras de materiais como no método de análise. Porém, podem sugerir polinização-cruzada, situação em que materiais de um campo podem ser aproveitados em outra área antes desconhecida, resultando em um produto inovador, como são os casos do Banco Osso e do tecido Oricla. A seleção por similaridade consiste em encontrar materiais substitutos que atendem aos atributos do projeto, como ocorreu no caso da Poltrona Kei, que utilizou o metal no espaldar, substituindo a madeira, a fim de atribuir maior resistência. A seleção por inspiração não trabalha com o método científico; pode ser adquirida de forma aleatória a partir da interação com materiais, produtos, por meio do benchmarking, pesquisa em livros etc, como ocorreu com o tecido Velaturas e o Biombo Conogó.

\section{Conclusões}

A análise dos outputs juntamente com as intenções dos candidatos, nos leva a acreditar que as autoras da categoria têxtil possuem maior preocupação com a sustentabilidade do que os autores de mobiliário. Nesse sentido, os produtos têxteis, apresentaram uma maior porcentagem de produtos que trazem inovação de alto impacto sustentável que a categoria de mobiliário, dando ênfase à exploração de materiais e à mescla de práticas artesanais com produção industrial, aumentando a acessibilidade dos produtos, mas mantendo o aspecto único de produto artesanal. Surge assim, uma oportunidade para inovar no campo de mobiliário, principalmente no que tange à acessibilidade, ao compartilhamento e à redução energética no processo de fabricação. A pesquisa se mostrou relevante por auxiliar na análise de impactos sociais, ambientais e também econômicos provocados por produtos considerados referência em design no mercado brasileiro, além de evidenciar que o emprego de materiais naturais quando usados de maneira responsável e visando a inovação é importante, mas representa uma parcela ainda pequena das estratégias de projeto possíveis e necessárias para gerar impactos positivos em relação à sustentabilidade. Acredita-se que as reflexões aqui apresentadas possam contribuir para mudanças no design de mobiliário e objetos têxteis. E em relação ao papel institucional do Prêmio Design do Museu da Casa Brasileira, que possam estimular outras iniciativas, de modo a fortalecer e difundir reflexões sobre seu significado junto ao desenvolvimento do design brasileiro, possibilitar eventuais revisões em sua organização, e estruturar novos mecanismos de disseminação do rico material reunido em seu acervo.

\section{Referências}

ASHBY, Mike e JOHNSON, Kara. Materials and Design. UK: Elsevier Ltd., 2010.

BONSIEPE, G. Design, cultura e sociedade. Trad. Itiro lida. São Paulo: Blucher, 2011.

BREZET, H.; HEMEL, C. EcoDesign: A promising approach to sustainable production and consumption, UNEP, France. 1997

CARDOSO, Rafael. Design para um mundo complexo. São Paulo: Cosac Naify, 2013.

CARNASCIALI, R. M. (2014). Gestão de design: contribuições da gestão da qualidade para a construção de parâmetros para avaliar o bom design (Dissertação de mestrado). Universidade Federal do Paraná, Curitiba.

CRADLE TO CRADLE CERTIFIED. Material Health Assessment Methodology. 3. ed. Virginia: MBDC, 2013. 90 p. 
DOUGHERTY, Brian. Design gráfico sustentável. 1. ed. São Paulo: Rosari, 2011. 184 p.

FACULTY OF INDUSTRIAL DESIGN ENGINEERING. EcoDesign strategy wheel. Disponível em: <http://wikid.io.tudelft.nl/WikID/index.php/EcoDesign_strategy_wheel>. Acesso em: 10 jul. 2017. FLICK, Uwe. Introdução à pesquisa qualitativa. Porto Alegre: Artmed, 2009.

INGOLD, Tim. Estar Vivo: Ensaios sobre movimento, conhecimento e descrição. São Paulo: Editora Vozes Ltda., 2015. p.301 - 314.

KAZAZIAN, Thierry. Haverá a idade das coisas leves: design e desenvolvimento sustentável. São Paulo: Editora Senac, 2005.

LEFTERI, Chris. Wood: Materials for Inspirational Design. 1. ed. London: RotoVision (March 1, 2005), 2005. $160 \mathrm{p}$.

LIMA, Marco Antônio Magalhães. Introdução aos materiais e processos para designers. Rio de Janeiro: Editora Ciência Moderna Ltda., 2006.

LÖBACH, Bernd. Design Industrial - bases para a configuração dos produtos industriais. Trad. Freddy Van Camp. São Paulo: Edgard Blucher, 2001.

MANZINI, Ezio. Design para Inovação Social e Sustentabilidade: comunidades criativas, organizações colaborativas e novas redes projetuais. Rio de Janeiro: E-papers, 2008.

MANZINI, Ezio; VEZZOLI, Carlo. O Desenvolvimento de Produtos Sustentáveis. São Paulo: Edusp, 2008.

MATERIABRASIL. Materioteca. Disponível em: <http://www.materiabrasil.com/explore>. Acesso em: 11 jan. 2018

Museu da Casa Brasileira. 28‥ Prêmio Design MCB. São Paulo, SP: Autor, 2014.

Museu da Casa Brasileira. 29․ Prêmio Design MCB. São Paulo, SP: Autor, 2015.

Museu da Casa Brasileira. 30․ Prêmio Design MCB. São Paulo, SP: Autor, 2016.

OCDE, Manual de Oslo: Proposta de Diretrizes para Coleta e Interpretação de Dados sobre Inovação Tecnológica. Publicado pela FINEP (Financiadora de Estudos e Projetos), 2a Edição, 2004.

SACHS, I. Caminhos para o Desenvolvimento Sustentável. Rio de Janeiro: Garamond, 2002.

SOUSA, Cyntia Santos Malaguti. Estudos de futuro e premiações em design: observatório de mudanças na cultura material. VII Congreso Latinoamericano de Enseñanza del Diseño, 2016.

ZENID, Geraldo José (coord.) Madeira: uso sustentável na construção civil. São Paulo: Instituto de Pesquisas Tecnológicas: SVMA, 2009. 